\title{
Erratum to: The Hidden Cost of Eating Meat in South Africa: What Every Responsible Consumer Should Know
}

\section{Astrid Jankielsohn ${ }^{1}$}

\section{Erratum to: J Agric Environ Ethics \\ DOI 10.1007/s10806-015-9581-8}

In addition to the original published article the author would like to acknowledge that any views or opinions in the article are personal views of the author and not the views of her employer ARC-Small Grain Institute.

The online version of the original article can be found under doi:10.1007/s10806-015-9581-8.

$\triangle$ Astrid Jankielsohn

jankielsohna@arc.agric.za

1 Agricultural Research Council-Small Grain Institute, Private Bag X29, Bethlehem 9700, South Africa 